\title{
BIOSURFACTANT PRODUCTION BY BACILLUS STRAINS RO7 AND R28 GROWN ON DIESEL
}

\author{
U.J.J. Ijah ${ }^{1^{*}}$, R. Olarinoye ${ }^{2}$ \\ ${ }^{1}$ Department of Microbiology, Federal University of Technology, P.M.B. 65, Minna, Nigeria \\ ${ }^{2}$ Department of Microbiology, University of Jos, Nigeria \\ "Email: udemijah@yahoo.com(corresponding author); Tel: 234-8035890201
}

\begin{abstract}
Bacteria isolated from waste lubricating oil polluted soil were screened for biosurfactant production using haemolytic activity on blood agar, emulsifying activity and surface tension. Seventeen $(45.95 \%)$ out of 37 isolates were heamolytic, indicating ability to produce biosurfactant. They were identified as species of Bacillus. Bacillus strains R07 and R28 exhibited maximum growth in diesel medium and formed less stable and stable emulsions, respectively. Based on these capabilities, the two strains were selected for biosurfactant production. Bacillus strain R28 had a higher emulsifying activity than R07 and was able to reduce the surface tension (ST) of diesel medium from 64 dynes/cm to 27 dynes $/ \mathrm{cm}$ while R07 reduced the ST to 35 dynes $/ \mathrm{cm}$ after 8 days. R28 generated $0.6 \mathrm{~g} / 100 \mathrm{ml}$ of biosurfactant after 8 days while R07 generated $0.4 \mathrm{~g} / 100 \mathrm{ml}$ over the same period. The biosurfactants produced by both strains contained substantial amount of phosphate and traces of protein but had no sugar. The biosurfactants were made up of $0.7 \% \quad 1,2$ diglycerides and $1.5 \%$ palmityl stearate for R07 and R28 respectively and were suspected to be phospholipids. The results obtained suggest that Bacillus strains R07 and R28 can produce biosurfactants that may be useful in the oil industry for enhanced oil recovery and bioremediation of oil spills.
\end{abstract}

(Keywords: Biosurfactant, bacteria, bioremediation, hydrocarbons, phospholipids)

\section{INTRODUCTION}

Biosurfactants are surface active agents produced by microorganisms when grown on a carbon source. Microbial biosurfactants have been known as partial or total substitutes for synthetic surfactants for the oil industry because of the facts that they are non-toxic, biodegradable and can be produced by fermentation of cheap substrates $[1,2,3]$ Biosurfactants vary in chemical properties and molecular size. They contain hydrophobic and hydrophilic moeities that give them the ability to orient between fluid phases, thus minimizing surface and interfacial tension at the surface and interface respectively [ 3,4].In recent time, biosurfactants have been widely used in industries, particularly food, pharmaceutical and petroleum industries as emulsifiers, solubilizers, antimicrobial agents and for enhanced oil recovery $[1,3,5]$.

Various genera of bacteria and yeasts have been associated with the production of biosurfactants. The major classes of biosurfactants are glycolipids, lipopeptides phospholipids, sophorolipids, surface active antibiotics, fatty acids/neutral lipids, polymeric biosurfactants and particulate biosurfactants [3, 4, 5]. Bacillus species are known to produce only few of these compounds. Bacillus subtitis and $B$. licheniformis have been reported to produce surfactin and lichenysin respectively which are lipopeptides while $B$. polymyxa produces polymyxin, a surface-active antibiotic [3]. Bacillus species are very versatile and widespread, yet many species have not been associated with biosurfactant production. The present study has therefore become necessary. The aim of the study was to produce biosurfactant from Bacillus strains isolated from waste lubricating oil polluted soil in Jos, Nigeria. Partial characterization of the biosurfactants produced was also undertaken.

\section{MATERIAL AND METHODS}

\section{Collection of samples}

Waste lubricating oil polluted soil was collected from different points in a mechanic workshop waste oil dump in Jos, Plateau State, Nigeria into polythene bags and transported to the laboratory for isolation of bacteria. Diesel was collected from Kaduna Refinery and Petrochemical Company (KRPC), Kaduna, Nigeria in a sterile bottle and transported to the laboratory. 


\section{Isolation and selection of biosurfactant producing bacteria}

Isolation of the bacteria was achieved by inoculating serially diluted soil samples into Nutrient agar (NA) plates. Filter sterilized antibiotics, cycloheximide (Sigma Chemical Company, U.S.A.) at a concentration of $40 \mathrm{~g} / \mathrm{ml}$ was incorporated to inhibit the growth of fungi [6,7]. The plates were incubated at $37^{\circ} \mathrm{C}$ for 48hours. Colonies which appeared on the NA plates were subcultured repeatedly on fresh NA plates to obtain pure cultures. The pure cultures were maintained on NA agar slants for further studies.

Biosurfactant producing bacteria were selected by screening the isolates on blood agar containing 5\% (v/v) blood and incubating at $28^{\circ} \mathrm{C}$ for 48hours Haemolytic activity was detected as the presence of a definite clear zone around a colony [8].

\section{Characterization and identification of isolates}

Only isolates which were haemolytic on blood agar were characterized based on Gram's reaction, and biochemical tests. The biochemical tests performed included reduction of nitrate, spore formation, utilization of citrate, production of indole, and methyl red-voges proskauer test (MR-VP). The ability of the isolates to utilize the following carbohydrates was tested: glucose, arabinose, inositol, xylose, fructose, mannitol and sucrose. The probable identities of the isolates were determined using the schemes of Krieg et al. [9].

\section{Determination of growth and emulsion stability levels in diesel}

The methods of Kokub et al [10] was followed in this experiment. Five millilitres of mineral salt medium of Antai [11] was dispensed in eighteen test tubes containing $0.05 \mathrm{~m} 1$ of diesel. After sterilization by autoclaving at $121^{\circ} \mathrm{C}$ for 15 minutes, the medium was allowed to cool before being inoculated with $0.1 \mathrm{ml}$ of nutrient brothgrown culture $\left(10^{6}\right.$ cells $)$. Three test tubes containing mineral salts medium with diesel were not inoculated with the nutrient broth grown - culture and served as a control. All test tubes were incubated at room temperature $\left(28 \pm 2^{\circ} \mathrm{C}\right)$ for 14 days. The turbidity which developed as a result of bacterial growth was monitored visually at the end of the incubation period and assigned + to +++ depending on the degree of turbidity.

\section{Biosurfactant production and isolation}

One hundred millilitres of mineral salt medium of Jacobucci et al. [12] was dispensed in conical flasks containing $0.1 \mathrm{ml}$ of diesel. After sterilization by autoclaving at $121^{\circ} \mathrm{C}$ for 15 minutes, the medium was allowed to cool before being inoculated with $1 \mathrm{mI}$ of nutrient brothgrown culture of the bacterial isolates. Two of the flasks were left uninoculated and served as a control. The flasks were incubated shaking (150rpm) at room temperature $\left(28 \pm 2^{\circ} \mathrm{C}\right)$. At 2 days interval for a duration of 8 days the emulsification activity, surface tension and biosurfactant content were determined.

\section{Measurement of emulsification activity}

The diesel oil was extracted with diethyl ether, leaving the medium and cells. Culture broth was made cell free by centrifugation at $2,800 \mathrm{rpm}$ for 15 minutes, $3.5 \mathrm{~m} 1$ of the cell free broth was vigorously shaken with $2 \mathrm{ml}$ of kerosene on a rotary shaker (Adolf Kuhner AG Schweiz, Germany) and left undisturbed. After one hour, optical density (OD) of the oil in water emulsion phase was measured at $610 \mathrm{~nm}$ using a spectrophotometer (Jenway 6300 spectrophotometer, UK). The OD reported as emulsification activity was expressed in centimeter. The emulsion index $\left(\mathrm{E}_{24}\right)$ was determined as the height of the emulsion layer, divided by the total height, multiplied by 100 .

Surface tension measurement was made on the supernatant samples by the ring method having a circumference of 4CMS, using a fisher surface tensiometer (Cole-Palmer Instrument Co., Bunker, IL, USA.) at room temperature.

\section{Determination of biosurfactant concentration}

The biosurfactant produced by the bacteria was isolated from cell free medium using chloroform, methanol and cell free supernatant in the ratio 2:1:3 by volume according to Rambeloarisoa $e t$ al. [14]. The quantity of the biosurfactant extracted was determined by taking the weight in gramme after being dried in the hot air oven.

\section{Extraction and analysis of biosurfactants}

Biosurfactant extraction was carried out using the Bligh and Dyer [15] method. The mineral 
salt medium was made cell free by centrifugation at 2,800rpm for 15 minutes (Gallenkamp, England). The supernatant was used for the extraction process. One millilitre of cell free supernatant was added to $3.75 \mathrm{ml}$ mixture of chloroform/methanol (1:2) and shaken for 15 minutes before centrifugation. The mixture separated into two phases. The lower phase (chloroform phase) contained the biosurfactant This was collected and dried in the hot air oven at $125^{\circ} \mathrm{C}$ for 1 hour. The biosurfactant was weighed in a container of known weight. The methanol and water layer which was the upper phase containing the proteins, sugars and other polar molecules was collected and the methanol was evaporated using a water bath. The liquid collected was used as the sample for the protein, sugar and phosphate determination.

\section{Protein determination}

Five millilitres $(5.0 \mathrm{ml})$ of Biuret reagent was added to $0.1 \mathrm{ml}$ sample in a test tube and mixed by shaking. The solution was warmed at $37^{\circ} \mathrm{C}$ for 10 minutes in a water bath and then allowed to cool. Similarly, a reaction was carried out using $0.1 \mathrm{ml}$ of $40 \mathrm{mg} / \mathrm{ml}$ protein standards as test, and $0.1 \mathrm{ml}$ of water as blank with Biuret reagent as carried out with the sample. The absorbance was read for both samples and standard against the blank at 540nm wavelength using a spectrophotometer (Ciba-coming, England).

\section{Sugar determination}

Sugars were determined by the anthrone method [16] using glucose (100ug/ml) as a standard [17].

\section{Inorganic phosphate determination}

Zero point eight millilitre $(0.8 \mathrm{~m} 1)$ of distilled water and $0.1 \mathrm{ml}$ of $10 \%$ trichloroacetic acid were added to $0.2 \mathrm{~m} 1$ of methanol/water filtrate obtained from cultures of Bacillus strains R07 and R28 respectively in test tubes. They were mixed well and then to $1 \mathrm{ml}$ of each sample was added $3.0 \mathrm{ml}$ of buffer (acetate $\mathrm{pH} 4$ ), $0.05 \mathrm{ml}$ of $5 \%$ ammonium molybdate and $0.5 \mathrm{ml}$ of $2 \%$ paramethyl aminophenol sulphate. After each dilution, the mixture was well mixed by shaking. One millilitre of working standard and $0.5 \mathrm{ml}$ of water for blank (control) were variously mixed with $0.5 \mathrm{~m} 1$ of $10 \%$ trichloroacetic acid in a test tube. The reaction was carried out as with the sample. After the test proceedings, the test tubes were allowed to stand for 5 minutes. The optical density was read at $720 \mathrm{~nm}$ wavelength.

The biosurfactant was identified using thin layer chromatography (TLC) according to the method of Beach et al. [18] for both analytical and preparative TLC.

\section{Analytical preparation}

TLC plates were washed and cleansed with aetone and coated with slurry of $35 \mathrm{~g}$ of silica gel mixed with $60 \mathrm{~m} 1$ of distilled water using a glass spreader to gel thickness of $0.25 \mathrm{~mm}$. The plates were air dried for 20 minutes and then oven dried for one hour at $110^{\circ} \mathrm{C}$ and cooled. The different lipid extracts were spotted along with some standards of both the neutral and polar lipids. Neutral lipids were separated using a onedimensional development solvent system of hexane/diethyl ether/acetic acid (270;30:3, $\mathrm{v} / \mathrm{v} / \mathrm{v})$.

\section{Preparative TLC}

Plates were prepared as described previously using $0.5 \mathrm{~mm}$ thickness of the silica gel $\mathrm{G}$ and developed in one-dimensional solvent system as described above. Lipid classes were identified by inserting the dry plates in a closed tank iodine vapour. The spots were marked after removing the plates from the tank and then the iodine vapour was allowed to evaporate. The identified spots were scraped off individually onto a Whatman No.1 filter paper inserted into glass funnel and eluted several times with $2 \mathrm{~m} 1$ chloroform: methanol, weight of each class in the neutral and polar lipids were calculated after weighing the filter paper with an analytical balance.

\section{RESULTS}

\section{Selection of biosurfactant producing strains}

Thirty seven bacterial isolates were obtained from the waste lubricating oil polluted soil and screened for biosurfactant production. Seventeen isolates $(44.7 \%)$ were haemolytic on blood agar indicating the potential of the isolates to produce biosurfactant. The seventeen potential biosurfactant producing strains (BPS) exhibited various levels of growth and emulsion in diesel medium (Table 1). However, five strains (R02, $\mathrm{R} 03$, R08, R13, R14) were unable to utilize diesel as a source of carbon and energy (Table 1). The 17 isolates were Gram positive, rod shaped spore formers. They however differed in 
Table 1: Level of growth and type of emulsion formed by Bacillus strains on diesel

\begin{tabular}{|c|c|c|}
\hline Strain & Growth of isolate after 14 days & Type of emulsion formed \\
\hline R 01 & + & SE \\
\hline R 02 & - & $\mathrm{NE}$ \\
\hline R 03 & - & $\mathrm{NE}$ \\
\hline R 04 & + & LS \\
\hline R 05 & + & LS \\
\hline R 06 & ++ & SE \\
\hline R 07 & +++ & LS \\
\hline R 08 & - & $\mathrm{NE}$ \\
\hline R 09 & + & SE \\
\hline R 10 & + & LS \\
\hline R 11 & + & LS \\
\hline R 12 & + & SE \\
\hline R 13 & - & $\mathrm{NE}$ \\
\hline R 14 & - & $\mathrm{NE}$ \\
\hline R 15 & ++ & SE \\
\hline R 16 & ++ & SE \\
\hline $\mathrm{R} 28$ & +++ & SE \\
\hline
\end{tabular}

\section{Legend:}

+++: Maximum growth, ++: moderate growth, +: minimal growth, -: No growth, SE: stable emulsion, LS: less stable emulsion, NE: No emulsion formed.

citrate, nitrate, indole and methyl red, Voges Proskauer reactions as well as abilty to utilize carbohydrates. All 17 BPS were identified as species of Bacillus. Based on efficient growth on diesel (Table 1) Bacillus strains R07 and R28 were selected for biosurfactant production using diesel.

\section{Surface activity of Bacillus strains. R07 and R28}

Table 2 shows the surface activity of the two biosurfactant producing Bacillus strains. The emulsification activity and emulsion index increased gradually with time. The emulsification activity increased from 1.61 to 1.89 for R28 and decreased from 1.73 to 1.64 for R07 after 8days. The emulsion index increased from $52.4 \%$ to $54.1 \%$ for R28 and decreased from $45.5 \%$ to $40.9 \%$ for R07 after 8days (Table 2).

Table 2: Emulsification activity and emulsion index of diesel medium by Bacillus strains.

\begin{tabular}{ccccc}
\hline \multirow{2}{*}{ Time(days) } & \multicolumn{2}{c}{ Emulsification activity } & \multicolumn{2}{c}{ Emulsion index (\%) } \\
\cline { 2 - 5 } & Strain R07 & Strain R28 & Strain R07 & Strain R28 \\
\hline 2 & 1.73 & 1.61 & 45.5 & 52.4 \\
4 & 1.82 & 1.64 & 45.5 & 52.4 \\
6 & 1.91 & 1.65 & 45.5 & 54.1 \\
8 & 1.64 & 1.89 & 40.9 & 54.1 \\
\hline
\end{tabular}

The two strains (R07 and R28) were able to reduce the surface tension of diesel medium from 64 dynes/cm to 35 dynes/cm for R07 and 27 dynes/cm for R28 after 8days. The amounts of biosurfactant secreted were $0.4 \mathrm{~g} / 100 \mathrm{ml}$ and $0.6 \mathrm{mg} / 100 \mathrm{ml}$ for R07 and R28 respectively after 8days (Table 3).

Table 3: Surface tension reduction of diesel and biosurfactant production by Bacillus strains

\begin{tabular}{ccccc}
\hline \multirow{2}{*}{ Time(days) } & \multicolumn{2}{c}{ Surface tension $($ dynes/cm) } & \multicolumn{2}{c}{ Biosurfactant conc. $(\mathrm{g} / 100 \mathrm{ml})$} \\
\cline { 2 - 5 } & Strain R07 & Strain R28 & Strain R07 & Strain R28 \\
\hline 2 & 47 & 38 & 0.1 & 0.2 \\
4 & 41 & 36 & 0.2 & 0.4 \\
6 & 38 & 32 & 0.2 & 0.4 \\
8 & 35 & 27 & 0.4 & 0.6 \\
\hline
\end{tabular}

* The surface tension of the diesel medium was 64 dynes/cm 


\section{Characterization of biosurfactants}

The results (Table 4) revealed that sugars (glucose. pentose, ketose, starch) were not detected in the biosurfactants. However, biosucfactant produced by both Bacillus strains (R07 and R28) had protein content of $0.57 \mathrm{~g} / 100 \mathrm{ml}$ each.

Table 4: Sugar, protein, and inorganic phosphate levels in biosurfactant produced by Bacillus strains

\begin{tabular}{|c|c|c|}
\hline \multirow[t]{2}{*}{ Parameter } & \multicolumn{2}{|c|}{ Bacillus strains } \\
\hline & R07 & R28 \\
\hline \multicolumn{3}{|l|}{ Sugar: } \\
\hline Glucose & Not detected & Not detected \\
\hline Pentose & Not detected & Not detected \\
\hline Ketose & Not detected & Not detected \\
\hline Starch & Not detected & Not detected \\
\hline Total protein $(\mathrm{g} / 100 \mathrm{ml})$ & 0.57 & 0.57 \\
\hline Inorganic phosphate $(\mathrm{mg} / 100 \mathrm{ml})$ & 3.0 & 3.5 \\
\hline
\end{tabular}

R07 had 3mg/100ml inorganic phosphate while R28 had $3.5 \mathrm{mg} / 100 \mathrm{ml}$ inorganic phosphate (Table 4). The biosurfactants were identified as phospholipids and consisted of1,2-diglycerides and palmityl stearate (Table 5).

Table 5: Biosurfactant fractions recovered from thin layer chromatography (TLC) and their composition.

\begin{tabular}{cccc}
\hline Organism & Biosurfactant & $\begin{array}{c}\text { Biosurfactant Fraction } \\
(\mu \mathrm{g}) \text { Recovered from } \\
\text { TLC }\end{array}$ & Composition \\
\hline Bacillus strain R07 & 1,2-Diglycerides & 0.014 & 0.70 \\
Bacillus strain R28 & Palmityl stereate & 0.03 & 1.50 \\
\hline
\end{tabular}

\section{DISCUSSION}

The results of this study have shown that seventeen out of the thirty-seven bacterial isolates examined were haemolytic. Carrilo et al. [8] had earlier established the relationship between haemolytic activity and biosurfactant production. The investigators proposed that haemolytic activity and biosurfactant production could be a good screening criterion in search of biosurfactant producing organisms. Thus, this characteristic has been useful in selecting potential biosurfactant producing bacteria in the study.

The haemolytic strains grew on diesel and formed emulsion. However, the level of growth and emulsion formation varied with the isolates probably due to the varying capabilities of the isolates to elaborate hydrocarbon degradative enzymes. Kokub et al. [10] used these parameters (level of growth and emulsion formation) to assess potent biosurfactant producers. The growth of haemolytic strain on hydrocarbons is often accompanied by the emulsification of the insoluble carbon source in the culture medium. In most cases, this has been due to the production of extracellular emulsifying agents during the breakdown of hydrocarbons [17]. Out of the seventeen hydrocarbon utilizing bacterial isolates, two bacterial isolates were identified as efficient hydrocarbon degraders based on their growth and ability to form emulsion on diesel.

The oil degrading/biosurfactant producing bacteria were identified as members of the genus Bacillus. Bacillus have been associated with hydrocarbon degradation and biosurfactant production by other investigators [7,13,20,21]. The two Bacillus strains (R07 and R28) lowered the surface tension of the diesel medium, from 64dynes/cm to $27-35$ dynes/cm after 8 days. This finding is similar to the report of Carrillo et al., [2], Christofi and Ivshina [8] and Nasr et al., [22]. Carrillo et al., [2] reported that after $24 \mathrm{~h}$ culture the surface tension of the broth was reduced from initial values of approximately 63 dynes $/ \mathrm{cm}$ to values close to 30 dynes $/ \mathrm{cm}$ in cellfree media. Similarly, Nasr et al., [22], reported a reduction of surface tension of culture medium from $65.9 \mathrm{mN} / \mathrm{m}$ to $23.3 \mathrm{mN} / \mathrm{m} 26.2 \mathrm{MN} / \mathrm{m}$ by Bacillus subtilis SN1 Bacillus cereus and SN12 respectively. The results obtained in the present 
study, particularly with Bacillus strain R28 is impressive because the potent biosurfactant producing microorganism among Bacillus spp known reduces the surface tension of water to 27 $\mathrm{mn} / \mathrm{m}$ [2, 23]. Although Bacillus strains R28 reduced the surface tension of the medium considerably the emulsion index of the oil medium caused by the organism ranged from $52.4 \%$ to $54.1 \%$ after 8days indicating less quantity of emulsion stabilizing agent in the growth medium [10]. Bacillus strain R07 had a lower emulsion index than Bacillus strain R28 meaning that R07 may be less potent in producing biosurfactant [4].

The emulsification activity of Bacillus strain R28 increased while that of Bacillus strain R07 decreased probably due to the potency of the biosurfactant produced. Cooper and Goldenberg [13] reported that biosurfactants have different components that are responsible for each activity.

Bacillus strain R28 produced higher amount $(0.6 \mathrm{~g} / 100 \mathrm{ml})$ of biosurfactant than R07 (which produced $0.4 \mathrm{~g} / 100 \mathrm{ml}$ ). This shows that the organisms, though members of the same genus, have varying capabilities in producing biosurfactants. This supports the report of Cooper and Goldenberg [13]. However, the biosurfactant yield in the present study is 5-6 times greater than the yield $(1 \mathrm{~g} / \mathrm{L})$ obtained by Cooper and Goldenberg [13] using two strains of Bacillus (Bacillus cereus IAF 346 and Bacillus strain IAF 343). Similarly, the biosurfactant yield by strains R07 and R28 is $3-5$ times greater than the yield $(1.2 \mathrm{~g} / \mathrm{l})$ obtained by Salehizadeh and Mohammadizad [25] usin Alcaligenes feccalis. The different in the capabilities of these organisms could be due to their enzyme activity.

This study showed that Bacillus, particularly Bacillus strain R07 and Bacillus strain R28 are potent hydrocarbon utilizers and biosurfactant producers. The organisms can be useful in industrial production of biosurfactants and in reclaiming oil spilled environment. The biosurfactants produced should be studied in relation to their application in enhanced oil recovery and oil spill bioremediation. This result is very significant because the yields of other components were poor while phosphate predominated. [13]. From the results of the chemical analysis, it appears the biosurfactants produced by the bacteria were phospholipids, comprising 1,2 diglycerids and palmity stearate. Phospholipids from hexadecane grown Acinetobacter sp have potent surfactant properties [4, 26, 27]. Phospholipids produced by Thiobacillus thiooxidans have also been reported to be responsible for wetting elemental sulphur which is necessary for growth [4].

\section{CONCLUSION}

Bacillus strains isolated from waste lubricating oil polluted soil have the ability to produce biosurfactant when grown on diesel. Bacillus strain R28 produced higher amount of biosurfactant than Bacillus stain R07. The biosurfactant were mainly phospholipids with good emulsifying qualities. Therefore, Bacillus strains from the Nigerian environment could be useful in industrial production of biosurfactant, and mopping up of oil spills in soil.

\section{REFERENCES}

1. Kosaric, N. (1992). Biosurfactants in industry. Pure Appl. Chemistry 64 (11):1731-1737.

2. Christofi, N. and Ivshins, I.B (2002). Microbial surfactants and their use in field studies of soil remediation. Appl.Microbiology 93: 915-929.

3. Musthusamy, K., Gopolakrishnan, S., Kochupappy, R. and Sivachdmabaram, P. (2008). Biosurfactants properties, commercial production and application. Curr Science 94 (6):736-74).

4. Kranth, H.G.K., Deo, P,G. and Veenanadig, N.K. (1999). Microbial production of biosurfactants and their importance. Curr. Science 77: 1166176.

5. Desia, J.D and Benat, I.M. (1997). Microbial production of surfactants and their commercial potential. Appl. Environ. Microbiology 61: 49-51.

6. Holm, E., and Jensen, V. (1972). Aerobic chemooirgantrophic bacteria of a Danish forest. Oikos 23: 248-260. 
7. Ijah, U.J.J. and Ukpe L.I. (1992). Biodegradation of crude oil by Bacillus strains 28A and 61B isolated from oil spilled soil. Waste Management 12:5560.

8. Carrillo, P., Mardaraz, C., PittaAlvarez., S. and Guiletti, A. (1996). Isolation and selection of biosurfactant producing bacteria. World J. Microbiol. and Biotechnology 12: 82-84.

9. Kreigh, H.R. and Holt, J.G eds. (1994). Bergey's Manual of Systematic Bacteriology. Wilkins Ltd, Baltimore,

10. Kokub, O., Shefeez, M., Kahlid, Z.M. and Malik, K. A. (1989). Isolation screening and characterization of biosurfactant production bacteria. Proceedings. of International Symposium of Biotechnology for Energy, Faisalah, Pakistan, pp. 221-232.

11. Antai, S.P. (1990). Biodegradation of Bonny light crude by Bacillus and Pseudomonas sp. Waste Management 10: 61-64.

12. Jacobucci, D.F.C., Vasconcelos, C.K., Matsuura, A., Falconi, F.A. and Durrant, I.R. (2001). Degradation of diesel oil by biosusrfactant producing bacterial strains. The Magazine of Environment Assessment and Remediation 8: 3-10.

13. Cooper, D.G. and Goldenberg B.G. (1987). Surface active agents from two Bacillus species. Appl. Environ. Microbiology 47: 173 - 176.

14. Rambeloarisoa, E., Rotani, J., Giush, G., Danujak, Z. and Bertrand, J. (1984). Degradation of crude oil by mixed population of bacteria isolated from seasurface foams. Mar. Biology 83: 69 -81.

15. Bligh, E.C., and Dyer, W.J. (1959). A rapid method of total lipid extraction and purification Canadian Biochem. Physiology 37:911 - 917.

16. Chaplin, M.F. and Kennedy, J.F. (1987). Carbohydrate Analysis, a Practical Approach. IRL Press, Oxford.
17. Rocha, C., San-Blast, F., San-Blast, G. and Vierina, L. (1992). Biosurfactant production by two isolate of Pseudomonas aeruginosa. World $J$. Microbiol. Biotechnology 8:125 - 128.

18. Beach, D.H., Holz, G. G. and Anekwe, G.E. (1979). Liquids of Leishmania promatigotes. J. Parasitology 65 (2): $203-216$.

19. Rosenberg, E. (1993). Exploiting microbial growth on hydrocarbon: New markets. Trends in Biotechnology 11(10): 419 - 424.

20. Shappard, J.D. and Mulligan, C. (1987). The production of surface by Bacillus subtilis grown on peat hydrolysate. Appl. Microbiol. Biotechnology 27: 110 $-116$.

21. Yousef, N., Simpson, D.R., Dancan, K.E., Mclnerney, M.J., Folmsbee, M., Fincher, T. and Knapp, R.M. (2007). Insitu biosurfactant production by Bacillus strains injected into a limestone petroleum reservoir. Appl. Environ. Microbiology 73 (4): 1239 - 1247.

22. Nasr, S., Soudi, M. R., Mehrnia, M. R. and Sarrafzadeh, M. H. (2009). Characterization of novel biosurfactant producing strains of Bacillus spp isolated from petroleum contaminated soil. Indian J. Microbiology 1(2): 54 61.

23. Ron, E. Z. and Rosenberg, E. (2001). Natural roles of biosurfactants. Environ. Microbiology 3: 229-236.

24. Salihu, A., Abdulkadir, I. and Almustapha, M.N. (2009). An investigation for Potential development on biosurfactants. Biotechnol. Molecular Biol. Reviews 3 (5): 111 117.

25. Salehizadeh, H. and Mohammadizad, S. (2009). Microbial enhanced oil recovery using biosurfactant produced by Alcaligenes faecalis. Iranian J. Biotechnology 7(4): 216 - 223. 
26. Fagade, O.E., Okolie, B.I. and Balogun, S. (2009). Effects carbon and nitrogen sources on biosurfactant producing Bacillus species isolates. Nig. J. Microbiology 23 (1): 1911 - 1917.

27. Rahman, P.K. and Gakpe, E. (2008). Production, characterization and applications of biosurfactants review. Biotechnology 7:360 -370. 